\title{
A viscoelastic-viscoplastic model for a thermoplastic and sensitivity of its rheological parameters to the strain-rate
}

\author{
Younès Saadallah \\ University of JIJEL, Algeria \\ sayounes@live.fr
}

\author{
Semcheddine Derfouf, Belhi Guerira \\ University of BISKRA, Algeria \\ chems.derfou@gmail.com, guerirabelhi@gmail.com
}

\begin{abstract}
The behavior of thermoplastics depends on several factors, mainly time and temperature. The present work is focused on an analysis of the time sensitivity of the viscoelastic and viscoplastic parameters of a rheological model. The material considered in this study is a polyamide 6 . The analogical model is represented by the Kelvin-Voigt viscoelastic mechanism mounted in series with a viscoplastic branch of Bingham. After a mathematical formulation of the equations governing the model, tensile tests at different strain rates are conducted. The model parameters are then identified by inverse analysis. The technique of genetic algorithms has been favored. A nonlinear dependence of these parameters on the rate of strain has been observed. The dependence function has been established by a nonlinear regression technique. The comparison of the experimental results with those obtained by the model reveals a satisfactory agreement, hence the validation
\end{abstract}

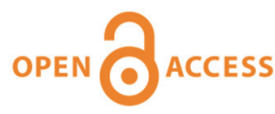

Citation: Saadallah, Y., Derfouf, S., Guerira, B., A viscoelastic-viscoplastic model for a thermoplastic and sensitivity of its rheological parameters to the strain-rate, Frattura ed Integrità Strutturale, 49 (2019) 666-675.

Received: 08.04 .2019 Accepted: 28.05.2019 Published: 01.07.2019

Copyright: (C) 2019 This is an open access article under the terms of the CC-BY 4.0, which permits unrestricted use, distribution, and reproduction in any medium, provided the original author and source are credited.

\section{INTRODUCTION}

7 hermoplastics are materials widely used in various industry applications. Indeed, these polymeric materials have relevant mechanical and electrical properties that allow them to adapt and meet different requirements in a wide variety of fields including automotive, aeronautics and medicine $[1,2]$. Therefore, the understanding of their behavior under external loading and in the conditions of their commissioning requires, in recent years, a considerable interest. 
Many models have been developed to represent the rheological behavior of thermoplastics [3-8]. Phenomenological models inspired by analog mechanisms such as spring, damper and pad combinations are well placed to represent viscoelastic and viscoplastic responses. The simplest mechanisms are the Maxwell and Kelvin-Voigt viscoelastic models and the Bingham viscoplastic model. The combination of these mechanisms in series or in parallel makes it possible to represent a wide variety of mechanical behaviors capable of representing linear or non-linear viscoelastic and viscoplastic rheological behaviors.

The mechanical behavior characterization of thermoplastic polymers is always a complicated task. This behavior depends on many external factors such as temperature and strain rate, but also other internal factors including entanglements, crosslinking and crystallinity degree [2,6]. This dependence is physically explained by their structure in macromolecular chains whose mobility, entanglement, branching and crosslinking are the main factors at the origin of the viscous aspect [9]. Taking into account these microscopic factors makes it possible to better understand the macroscopic response and contributes to the establishment of relevant behavior models [10]. On the other hand, it is very difficult to account the influence of all the physical mechanisms in the behavior laws, from which the application of the phenomenological models . Demonstration of time behavior dependence is usually done by means of creep, relaxation or tensile tests at different strain rates. Experimental data is used to identify the model parameters under consideration using different methods.

Two major classes of methods are distinguished: analytical-graphical methods and inverse identification methods. Methods based on the formulation of inverse problems are the most used. They consist in the minimization of a function that establishes the gap between the experimental data and the results of the modeling. It is therefore a question of solving an optimization problem by setting up the appropriate calculation algorithm. In recent years, so-called metaheuristic optimization methods have been developed. As an example, genetic algorithms and ant colony algorithms are mentioned [refs]. Genetic algorithms based on evolutionary ideas of natural selection and genetics [11, 12]. They serve as powerful tools for solving very complicated optimization problems when the derivative of the objective function is very difficult to obtain or does not exist $[13,14]$. So, they saw their use for determining material parameters for models with a large number of parameters. The authors of the reference works [14-16] used them for the estimation of the viscoelastic parameters while those of the references $[6,17,18]$ used them for the determination of the viscoplastic parameters.

Numerous studies relating to the sensitivity of polymer behavior to time and temperature are identified in the literature. The references [19-24] are cited for illustrative purposes. Since mechanical behavior models are controlled by parameters, it is natural that these parameters also depend on time and temperature. Several researchers have investigated the relationship of the sensitivity of elastic parameters, including Young's modulus and elastic limit, to strain rate and temperature $[20,21,25,26]$. It is found that increasing the rate of strain increases the elastic parameters while the increase in temperature decreases them. On the other hand, although there is also much published work on the sensitivity of viscoplastic parameters, few of them have established dependence functions.

The present work is an analysis of the sensitivity to strain rate of the parameters of a viscoelastic-viscoplastic behavior model applied to thermoplastic materials. The proposed model is an assembly of the Kelvin-Voigt viscoelastic mechanism in series with the Bingham generalized viscoplastic mechanism with nonlinear hardening. The material under study is a polyamide 6. Tensile tests at different strain rates were conducted to serve as data necessary for the identification of model parameters. The latter are identified by means of an inverse analysis based on the technique of genetic algorithms. As testmodel results are confronted and good consistency is enforced, dependency functions are then derived from non-linear regression.

\section{RHEOLOGICAL MODELING}

\section{Viscoelastic-viscoplastic model}

7 he proposed rheological model is illustrated in Fig. 1. It is a series assembly of two mechanisms, one representing the viscoelastic behavior and the other the viscoplastic behavior. The viscoelastic mechanism is represented by the instantaneous Kelvin-Voigt model, consisting of a spring representing instantaneous elasticity mounted in series with a parallel combination of another spring and another damper thus reproducing a viscoelasticity. This model is adopted to describe the viscoelastic behavior of polymers [27, 28]. The viscoplastic mechanism, which is activated only when the loading exceeds a critical value known by the plasticity threshold, is described by the generalized model of Bingham defined by the parallel association of a pad indicating the threshold of plasticity, a non-linear spring representing the work hardening of the material and a damper simulating the viscoplastic strain. The Bingham model is applied to 
describe the viscoplastic behavior of wood $[29,30]$ and polymers [28, 31]. The proposed model, by its components, is extensible and therefore likely to simulate a wide variety of materials.

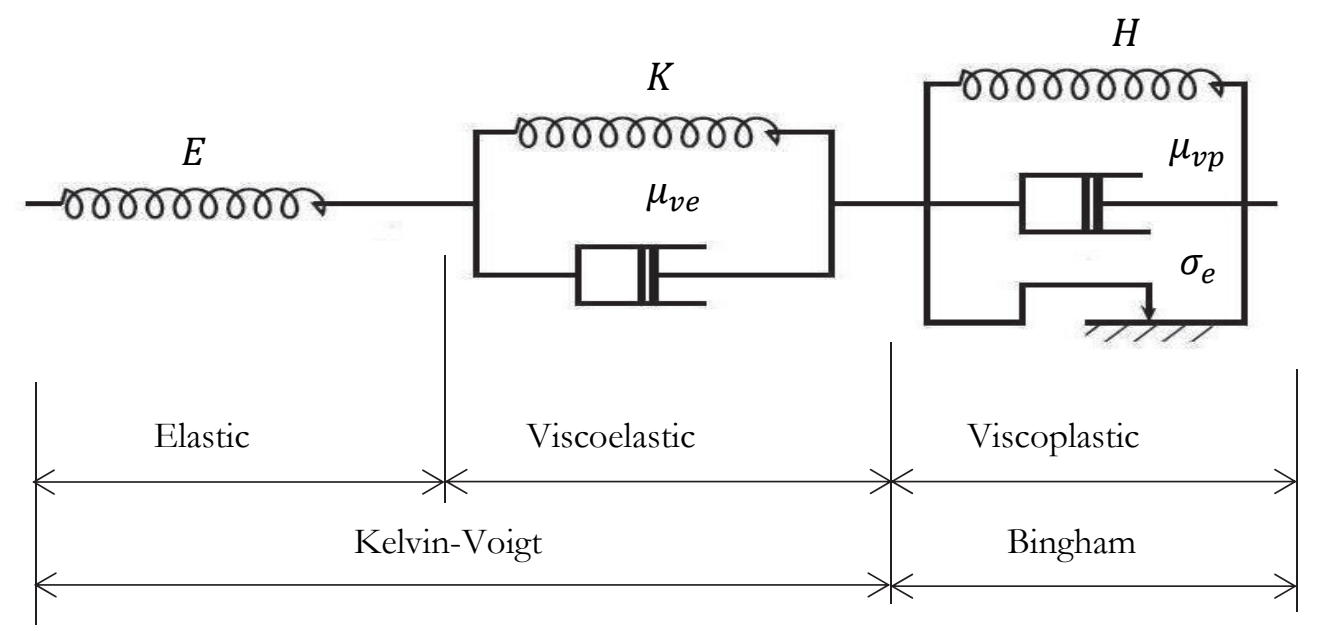

Figure 1: Viscoelastic-viscoplastic rheological model

\section{Mathematical formulation}

The viscoelastic response is represented by the rheological model composed of Kelvin-Voigt with instant elasticity. It follows that the total viscoelastic strain $\varepsilon$ is all of an instantaneous elastic part $\varepsilon_{e}$ and a deferred part $\varepsilon_{v e}$.

$$
\varepsilon=\varepsilon_{e}+\varepsilon_{v e} .
$$

The stress $\sigma$ generated in the viscoelastic mechanism is expressed by:

$$
\sigma=E \varepsilon_{e}=K \varepsilon_{v e}+\mu_{v e} \dot{\varepsilon}_{v e}
$$

Where $\mathrm{E}, \mathrm{K}$ and $\mu_{v e}$ represent the viscoelastic parameters of the model (Fig. 1).

The speed of instantaneous elastic strain $\dot{\varepsilon}_{e}$ being zero, replacing $\varepsilon_{e}$ by its value, we obtain:

$$
\sigma=\frac{E}{E+K}\left(K \varepsilon+\mu_{v e} \dot{\varepsilon}\right)
$$

Where $\dot{\varepsilon}$. is the rate of total viscoelastic strain.

The threshold of plasticity being reached, the response of the material takes a second component that is the viscoplastic strain $\varepsilon_{v p}$. The latter is described by the generalized model of Bingham with nonlinear hardening.

$$
\varepsilon=\varepsilon_{e}+\varepsilon_{v e}+\varepsilon_{v p}
$$

It follows that the equations governing the viscoplastic behavior of material are expressed by:

$$
\sigma=\sigma_{e}+H\left(\varepsilon_{v p}\right)^{n}+\mu_{v p} \dot{\varepsilon}_{v p}
$$

Where $\mathrm{H}, \mathrm{n}$ and $\mu_{\iota p}$ represent the viscoplastic parameters of the model (Fig. 1); $\sigma_{e}$ is the elastic limit. This allows us to write: 


$$
\sigma=\sigma_{e}+H\left(\varepsilon-\varepsilon_{v e}-\varepsilon_{e}\right)^{n}+\mu_{v p}\left(\dot{\varepsilon}-\dot{\varepsilon}_{v e}-\dot{\varepsilon}_{e}\right)
$$

replacing the elastic strain, the viscoelastic strain and its velocity by their formulas, and considering that the rate of elastic strain is zero, we obtain:

$$
\sigma=\sigma_{e}+H\left(\varepsilon-\frac{\sigma}{K}\left(1-\exp \left(-\frac{K t}{\mu_{v e}}\right)\right)-\frac{\sigma}{E}\right)^{n}+\mu_{\nu p}\left(\dot{\varepsilon}-\frac{\sigma}{\mu_{v e}}\left(\exp \left(-\frac{K t}{\mu_{v e}}\right)\right)\right)
$$

Since the above equation is non-linear, numerical methods must be used for its resolution. Several methods are used to solve this kind of problem. Here is favored the bisection method [32]. The implementation is done under Matlab.

\section{MATERIAL AND EXPERIMENTATION}

\section{Material of study}

7 he material under study is a polyamide 6. It is a technical thermoplastic named TECAMID 6 sold in sheets $7 \mathrm{~mm}$ thick. The conditions under which the tests are carried out are summarized in a temperature of $300 \mathrm{~K}$ and a humidity of $20 \%$. The specimen's geometry was established according to ASTM D638. They were cut by CNC milling.

\section{Testing machine}

The test machine is a INSTRON 5969 with a capacity of $50 \mathrm{KN}$. It is equipped with a contactless video extensometer. This one allows to correct some problems like those related to the sliding of the edges of knife and the inertia of moving parts. The data is processed using the Bleuhill 3 control and acquisition system.

\section{perimental results}

Tensile tests at different constant strain rates are conducted. The strain rates correspond to the speeds of the crosshead movement. They are of the order of $(0.0000646,0.000625,0.00612,0.0556) \mathrm{min}^{-1}$. The curves obtained, as shown in Fig. 2, clearly demonstrate the strain rate sensitivity of the tensile behavior.

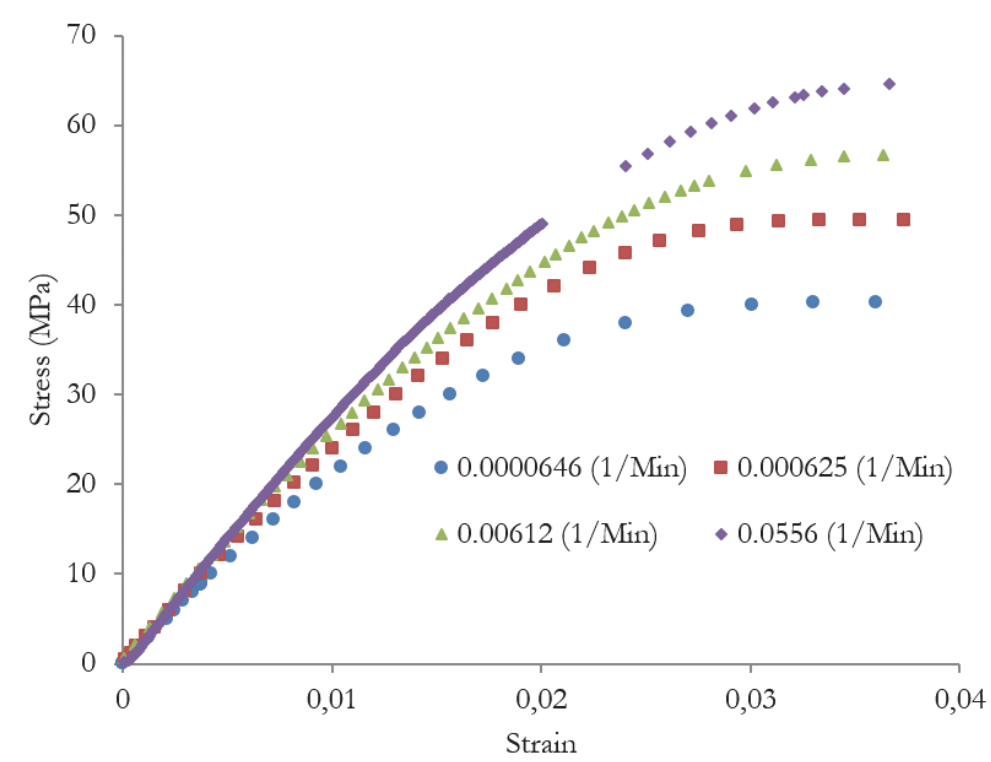

Figure 2: Stress-strain curves of a polyamide 6 at different strain rates. 
The results obtained are described by the strain-strain curves of Fig. 2. It clearly shows a time-dependent rheological behavior. The strain rate plays remarkably influence on the stress-strain relationship both in the viscoelastic domain and in the viscoplastic domain. In terms of quality, the shape of the curves is insensitive to the speed of strain. However, quantitatively, the difference between the curves as a function of the rate of strain is clearly distinguished. There is an increase in the resistance of the material with the increase in the rate of strain.

\section{IDENTIFICATION OF RHEOLOGICAL PARAMETERS}

\section{Genetic algorithms}

I $\mathrm{t}$ is generally accepted that genetic algorithms [11] are particularly suited to multidimensional global search problems where the search space potentially contains multiple local minima [14]. Unlike other research methods, genetic algorithms do not require a thorough knowledge of the search space, such as the limits of probable solutions or the derivatives of functions. They begin with a set of potential solutions chosen at random; and evolve by iteratively applying a set of stochastic operators, known as selection, crossover, and mutation. No gradient information is needed. Only the objective function and the constraints are necessary to determine the solution of the problem. Thus, they have the possibility of facing problems with a complicated objective function, where its derivative is difficult to obtain, or even non-existent. As a result, these techniques are well placed to be applied in the present work.

\section{Identification of parameters}

The identification of the three viscoelastic $\left(\mathrm{E}, \mathrm{K}, \mu_{v e}\right)$ and four viscoplastic $\left(\sigma_{e}, \mathrm{H}, \mathrm{n}, \mu_{v p}\right)$ parameters is done by setting up respectively objective functions $Q_{v e}$ and $Q_{v p}$ minimizing the difference between the experimental measurements and the values of the model. So the optimization problems are formulated as follows:

$$
\begin{aligned}
& Q_{v e}\left(E, K, \mu_{v e}, \sigma_{c}, \sigma_{e x}\right)=\sum_{i=1}^{N}\left(\sigma_{e x}^{i}-\sigma_{c}^{i}\left(E, K, \mu_{v e}, \varepsilon, \dot{\varepsilon}\right)\right)^{2} \\
& \mathcal{Q}_{\nu p}\left(\sigma_{e}, H, n, \mu_{\nu p}, \sigma_{c}, \sigma_{e x}\right)=\sum_{i=1}^{N}\left(\sigma_{e x}^{i}-\sigma_{c}^{i}\left(\sigma_{e}, H, n, \mu_{\nu p}, \varepsilon, \dot{\varepsilon}\right)\right)^{2}
\end{aligned}
$$

Where $\mathrm{N}$ is the number of measurement points; $\sigma_{\mathrm{ex}}^{\mathrm{i}}$ and $\sigma_{\mathrm{c}}^{\mathrm{i}}$ respectively represent the experimental stress and simulated by the model.

The genetic algorithm optimization technique was applied in the Matlab environment to determine the viscoelastic and viscoplastic parameters of the model.

The elastic limit corresponds to the stress at which the material begins to have a permanent strain. For metals, this limit is practically determined at the stress at which a $0.2 \%$ strain is attained. Moreover, according to the references $[8,33]$, polymers have an elastic limit corresponding to a strain of $1 \%$, where the stress-strain curve becomes clearly nonlinear.

\section{RESULTS AND DISCUSSION}

$\mathrm{T}$

he proposed viscoelastic-viscoplastic rheological model was applied to simulate the behavior of the polyamide 6 material. The following sections present the experimental and simulation results obtained from a tensile test at several strain rates.

\section{Identified parameters}

Tabs. 1 and 2 represent respectively the viscoelastic and viscoplastic identified parameters. It can be seen that the modulus $\mathrm{E}$ is constant and independent of the strain rate, whereas the viscoelastic parameters $\mathrm{K}$ and $\mu_{v e}$ depend considerably on it. It should be noted that with the increase of the strain-rate, the parameter $\mathrm{K}$ increases while the $\mu_{v e}$ parameter decrease. 
As for the viscoplastic parameters, the coefficient of work hardening is constant whatever the strain-rate, or the other viscoplastic parameters are a function of the strain-rate. The higher the strain-rate, the greater the elastic limit $\sigma_{e}$ and the modulus $\mathrm{H}$, and the lower the viscoplasticity coefficient $\mu_{i p}$.

\begin{tabular}{cccc}
\hline Strain-rate $\left(\mathrm{min}^{-1}\right)$. & $E(G P a)$ & $K(G P a)$ & $\mu_{v e}(G P a . m i n)$ \\
0.0000646 & 2.9765 & 7.3122 & 23.8816 \\
000625 & 2.9765 & 12.2063 & 5.0066 \\
0.00612 & 2.9765 & 18.6363 & 0.7380 \\
0.0556 & 2.9765 & 32.3085 & 0.0640 \\
\hline
\end{tabular}

Table 1: Viscoelastic parameters

\begin{tabular}{ccccc}
\hline Strain-rate $\left(\mathrm{min}^{-1}\right)$ & $\sigma_{e}(\mathrm{MPa})$ & $H(\mathrm{MPa})$ & $n$. & $\mu_{\nu p}(\mathrm{MPa} . \mathrm{min})$. \\
0.0000646 & 22.0151 & 69.8468 & 0.3072 & 6962.33 \\
0.000625 & 20202 & 94.9441 & 0.3072 & 3044.22 \\
0.00612 & 24.8992 & 122.883 & 0.3072 & 210.346 \\
0.0556 & 26 & 155.818 & 0.3072 & 23.11376 \\
\hline
\end{tabular}

Table 2: Viscoplastic parameters

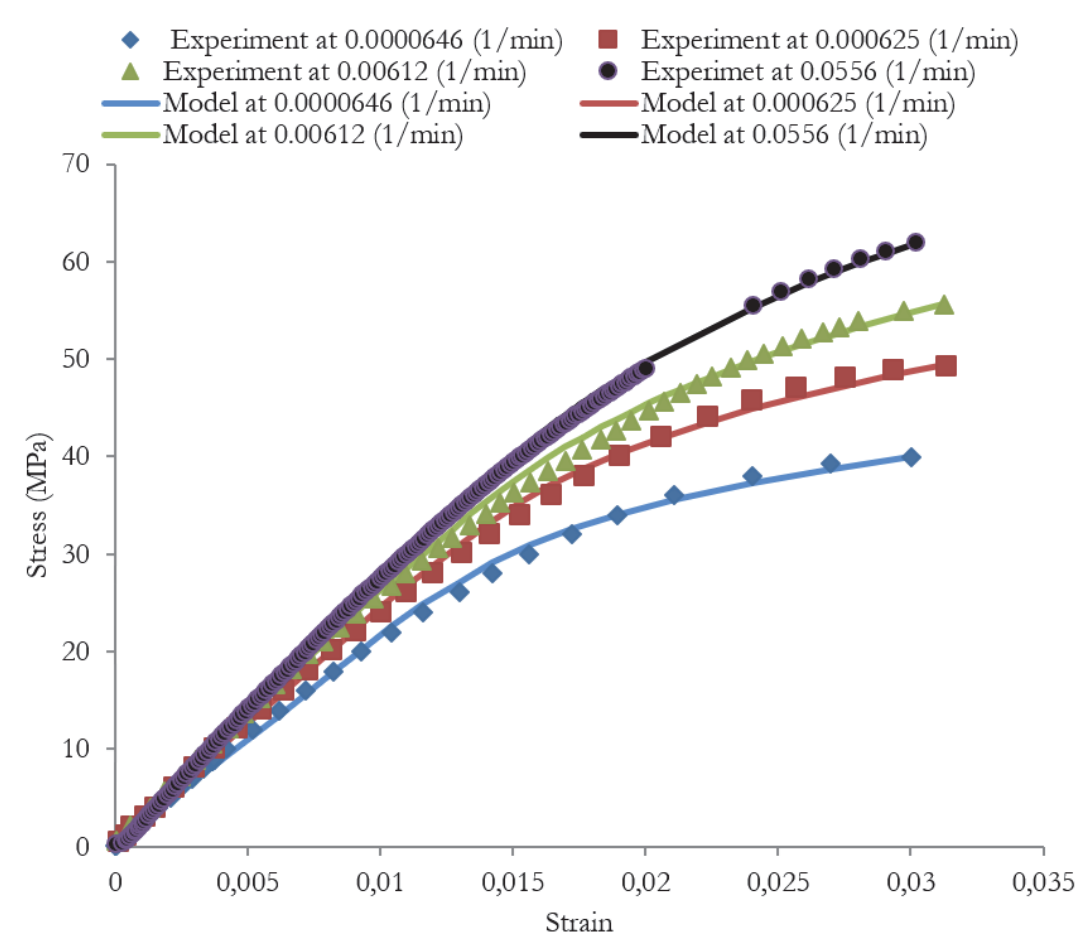

Figure 3: Comparison test-model of the stress-strain curves of Polyamide 6 at various strain-rates 


\section{Stress-strain curves}

To evaluate the relevance of the rheological model taken into account, the stress-strain curves of the experiment and those of the simulation, at four strain-rates, are compared. Below the elastic limit, the stress is related to the strain by a linear function. The threshold of plasticity being reached, the curve takes another pace. Indeed the spring of the viscoplastic mechanism connecting the stress to the strain with a nonlinear function is at the origin of the nonlinearity observed on the curve. The error between the test-model results is almost insignificant.

\section{Sensitivity of the elastic limit to the strain-rate}

The stress corresponding to the elastic limit depends considerably on the strain-rate. Indeed, the higher the strain-rate, the greater the stress corresponding to the elastic limit. Fig. 4 illustrates the dependence of the elastic limit on the strain-rate. In the references $[19,20,34-36]$, the authors extensively discussed the sensitivity of the elastic limit to the strain rate. Different functions have been established. It should be mentioned that the elastic limit also depends on the temperature, an aspect that is not considered in this study because the tests were conducted at constant room temperature. In the present work, the dependence can be expressed by a power law as illustrated in Fig. 4.

In addition, Fig. 5 shows the elastic limit versus the logarithm of the strain-rate. There is a linear increase in the elastic limit as a function of the strain-rate. This is in perfect agreement with other work on polymers with references [35-37]. In another plane, the strain corresponding to the elastic limit is insensitive to the strain-rate.

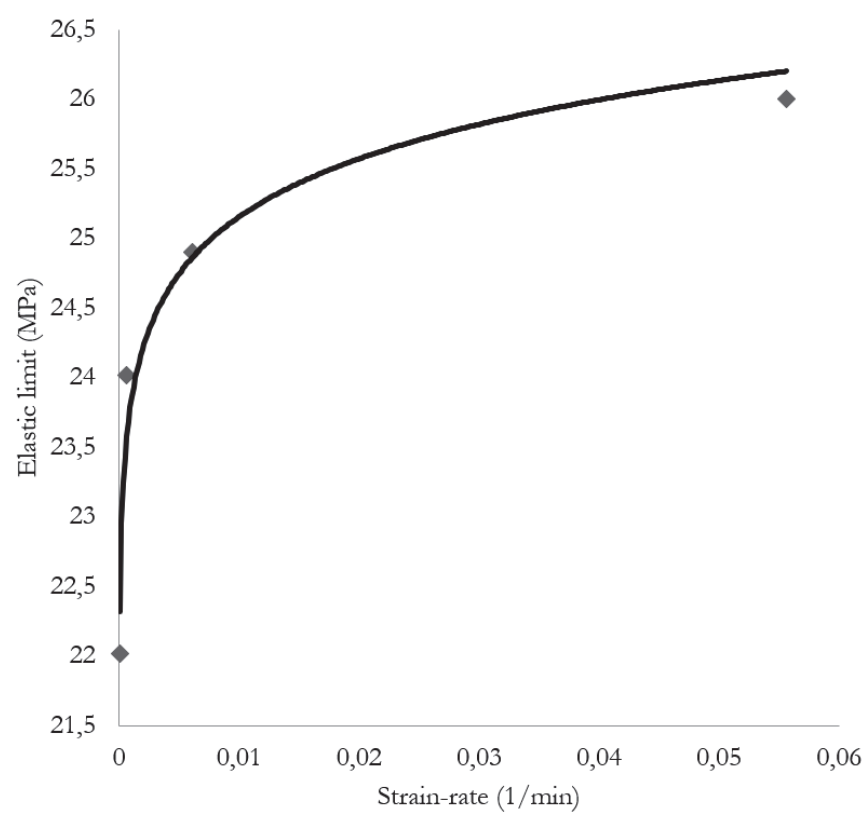

Figure 4: Sensitivity of the elastic limit to the strain-rate.

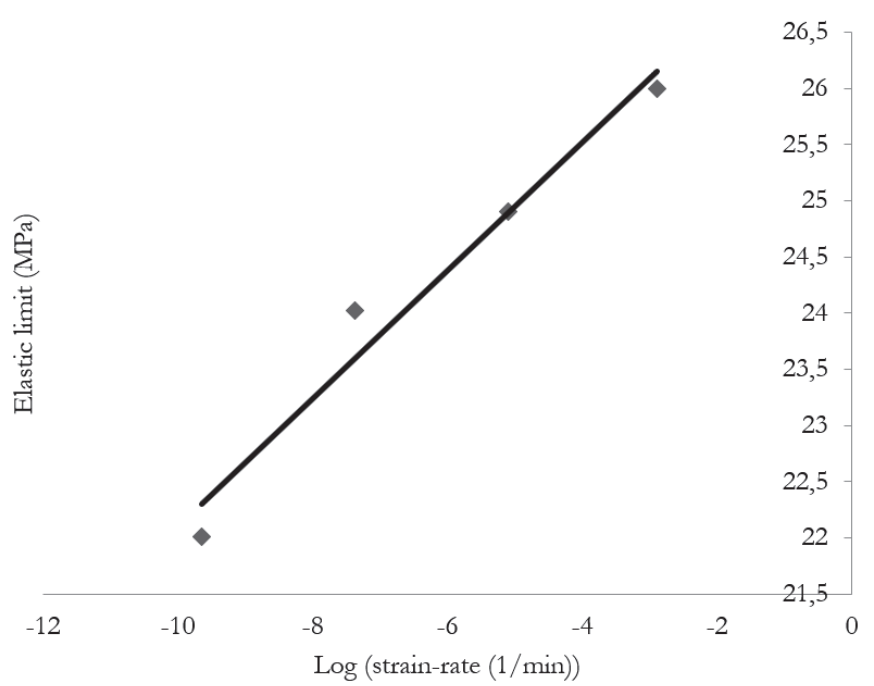

Figure 5: Linearity of elastic limit at the logarithm of the strainrate

\section{Sensitivity of the parameters to the strain-rate}

In order to verify the dependence of the viscoelastic and viscoplastic parameters of the strain-rate, four different speeds were taken into account in the tensile tests. Following the identification step, it turned out that the elastic modulus $\mathrm{E}$ is independent of the strain-rate while the other two viscoelastic parameters show non-linear dependency. Referring to Fig. 6 , it is noted that the $\mathrm{K}$ module increases with the increase of the strain-rate while the viscosity parameter $\mu_{\nu e}$ decreases. On the viscoplastic plane, the work hardening coefficient $\mathrm{n}$ is independent of the strain rate whereas the other two viscoplastic parameters depend on it and are connected to it with nonlinear functions. Referring to Fig. 7, an analogy can be observed qualitatively between the viscoplastic parameters $\mathrm{H}$ and $\mu_{v p}$ on the one hand and the viscoelastic parameters $\mathrm{K}$ and $\mu_{v e}$ respectively on the other hand. Thus with the increase of the strain-rate, the module $\mathrm{H}$ increases while the parameter $\mu_{\nu p}$ decreases. 

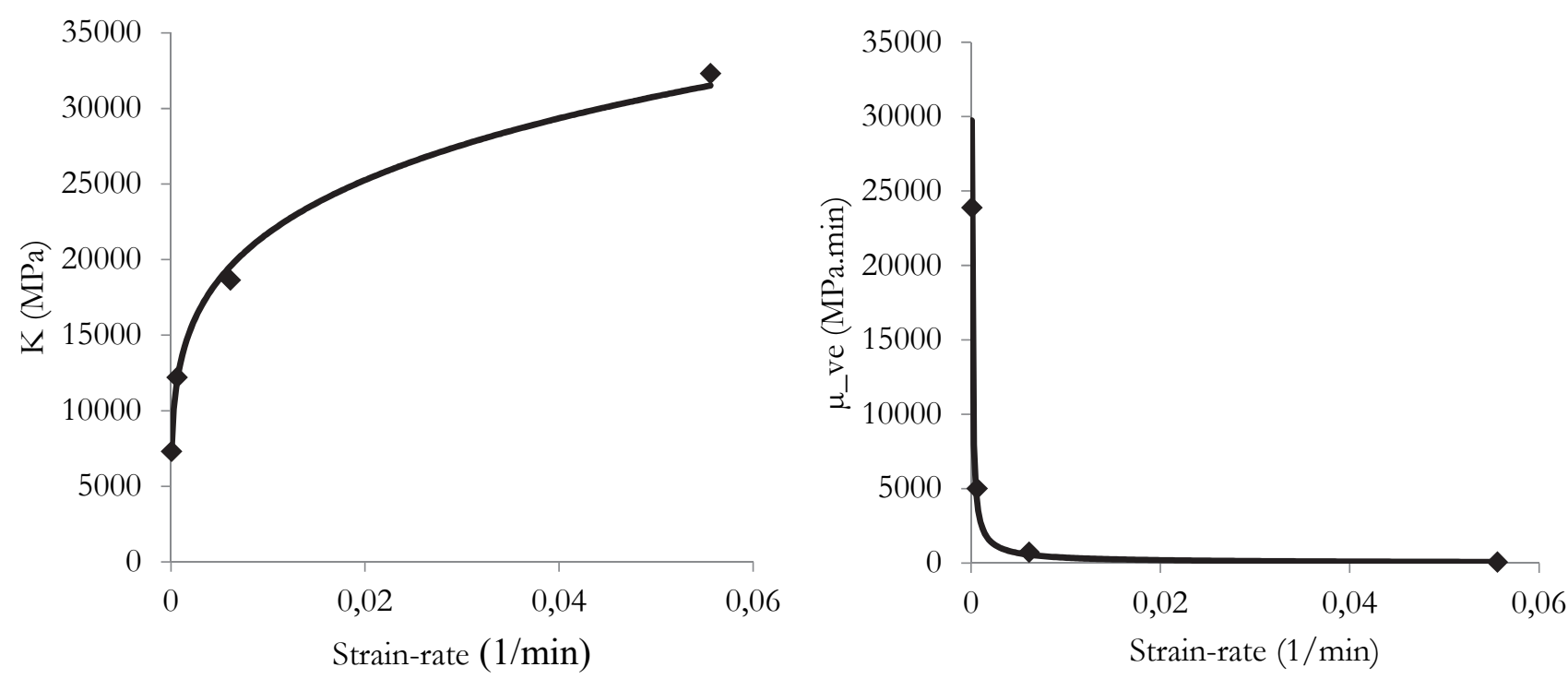

Figure 6: Dependence of viscoelastic parameters at the strain-rate
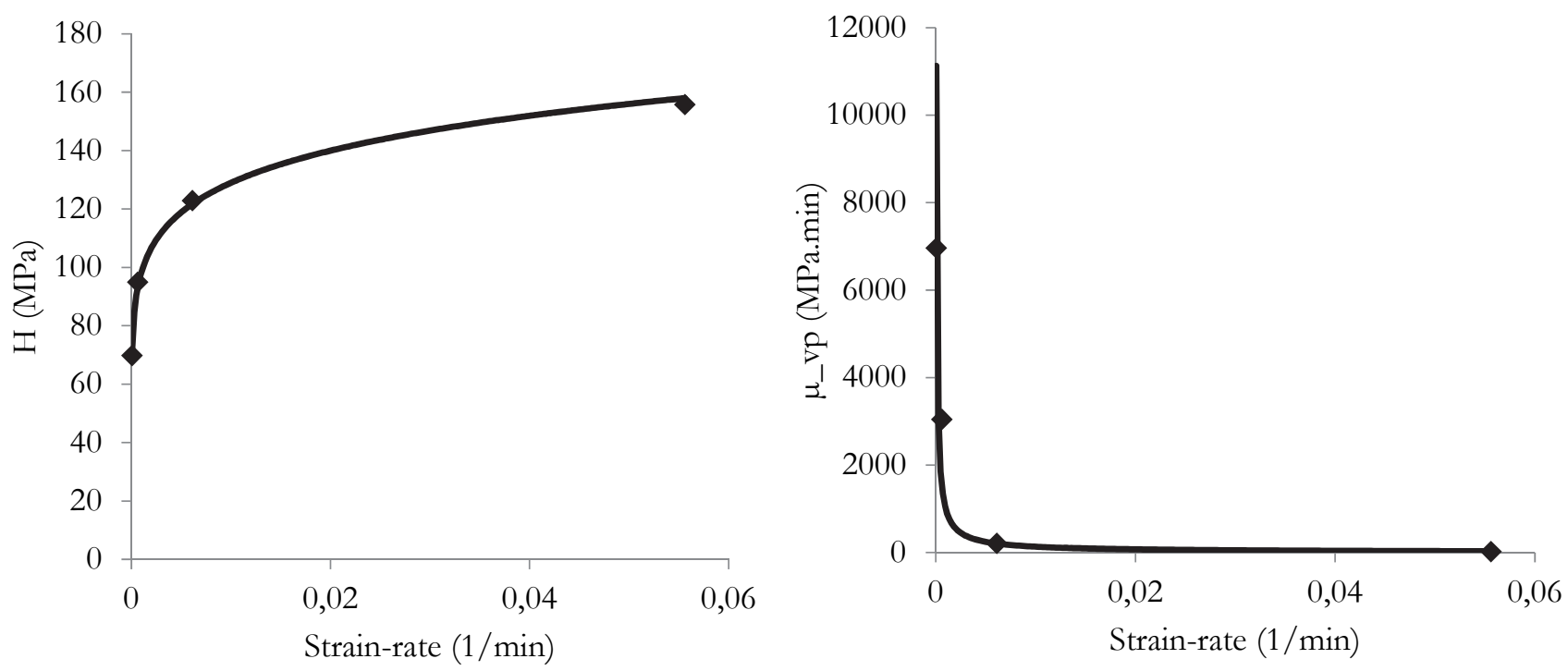

Figure 7: Dependence of viscoplastic parameters at the strain-rate

To define the functions that represent the mathematical relationship of the strain rate with the viscoelastic and viscoplastic parameters, a nonlinear regression technique is considered. As a result, a power law connects both the viscoelastic parameters and the viscoplastic parameters to the strain-rate. The curves that represent the sensitivity of the viscoelastic parameters to the strain-rate are illustrated in Fig. 6. The sensitivity of the viscoplastic parameters is illustrated in Fig. 7. With the exception of the elastic modulus $\mathrm{E}$ and the coefficient of hardening $\mathrm{n}$ which are independent of it, the functions obtained are shown in Tab. 3 .

\begin{tabular}{ccccc}
\hline$K$ & $\mu_{v e}$ & $\sigma_{e}$ & $H$. & $\mu_{v p}$ \\
$58881 \dot{\varepsilon}^{0,21}$ & $6,6166 \dot{\varepsilon}^{-0,87}$ & $28,059 \dot{\varepsilon}^{0,02}$ & $222,27 \dot{\varepsilon}^{0,12}$ & $2,3512 \dot{\varepsilon}^{-0,88}$ \\
\hline
\end{tabular}

Table 3: Relationship of the parameters with the strain-rate 


\section{CONCLUSION}

I $\mathrm{n}$ this work, we have mainly studied the sensitivity to the strain-rate of the viscoelastic and viscoplastic parameters of a rheological model applied to thermoplastics. The proposed behavior model takes into account several elementary responses including instant elasticity, viscoelasticity, viscoplasticity and hardening. The identification of the parameters was carried out on the basis of the experimental results obtained following a simple tensile test at different strain rates. The parameters were identified by means of inverse analysis by genetic algorithms. The comparison of the test-model results reveals a very good coherence. Except the modulus of elasticity and the exponent of work hardening, the results obtained reveal a strong dependence of the other viscoelastic and viscoplastic parameters to the strain rate. A nonlinear regression technique has made it possible to establish dependence functions which show relations in power law.

\section{REFERENCES}

[1] Maurel-Pantel, A., Baquet, E., Bikard, J., Bouvard, J. L., and Billon, N. (2015). A thermo-mechanical large deformation constitutive model for polymers based on material network description: Application to a semi-crystalline polyamide 66, International Journal of Plasticity, 67, pp. 102-126.

[2] Colak, O. U. (2005). Modeling deformation behavior of polymers with viscoplasticity theory based on overstress, International Journal of Plasticity, 21, pp. 145-160.

[3] Müller, S., Kästner, M., Brummund, J., and Ulbricht, V. (2011). A nonlinear fractional viscoelastic material model for polymers, Computational Materials Science, 50, pp. 2938-2949.

[4] Zhang, C., and Moore, I. D. (1997). Nonlinear mechanical response of high density polyethylene. Part II: Uniaxial constitutive modeling, Polymer Engineering \& Science, 37, pp. 414-420.

[5] Miled, B., Doghri, I., and Delannay, L. (2011). Coupled viscoelastic-viscoplastic modeling of homogeneous and isotropic polymers: Numerical algorithm and analytical solutions, Computer Methods in Applied Mechanics and Engineering, 200, pp. 3381-3394.

[6] Abdul-Hameed, H., Messager, T., Zaïri, F., and Naït-Abdelaziz, M. (2014). Large-strain viscoelastic-viscoplastic constitutive modeling of semi-crystalline polymers and model identification by deterministic/evolutionary approach, Computational Materials Science, 90, pp. 241-252.

[7] Zaïri, F., Naït-Abdelaziz, M., Woznica, K., and Gloaguen, J.-M. (2007). Elasto-viscoplastic constitutive equations for the description of glassy polymers behavior at constant strain rate, Journal of Engineering Materials and Technology, 129, pp. 29-35.

[8] Tscharnuter, D., Jerabek, M., Major, Z., and Pinter, G. (2012). Uniaxial nonlinear viscoelastic viscoplastic modeling of polypropylene, Mech Time-Depend Mater, 16, pp. 275-286.

[9] Ferry, J. D. (1980) Viscoelastic properties of polymers, John Wiley \& Sons.

[10] Davoodi, B., Muliana, A., Tscharnuter, D., and Pinter, G. (2015). Analyses of viscoelastic solid polymers undergoing degradation, Mech Time-Depend Mater, 19, pp. 397-417.

[11] Golberg, D. E. (1989). Genetic algorithms in search, optimization, and machine learning, Addion wesley.

[12] Holland, J. H. (1975). Adaptation in natural and artificial systems: an introductory analysis with applications to biology, control, and artificial intelligence, U Michigan Press.

[13] McCall, J. (2005). Genetic algorithms for modelling and optimisation, Journal of Computational and Applied Mathematics, pp. 184, 205-222.

[14] Kohandel, M., Sivaloganathan, S., and Tenti, G. (2008). Estimation of the quasi-linear viscoelastic parameters using a genetic algorithm, Mathematical and Computer Modelling, 47, pp. 266-270.

[15] Feng, X.-T., Chen, B.-R., Yang, C., Zhou, H., and Ding, X. (2006). Identification of visco-elastic models for rocks using genetic programming coupled with the modified particle swarm optimization algorithm, International Journal of Rock Mechanics and Mining Sciences, 43, pp. 789-801.

[16] Wang, G. Y., and Wang, M. (2011). Multi-Parameter Identification of Geomembrane Viscoelastic-Plastic Creep Constitutive Model by Genetic Algorithm, In Applied Mechanics and Materials, pp 182-188, Trans Tech Publ.

[17] Dusunceli, N., Colak, O. U., and Filiz, C. (2010). Determination of material parameters of a viscoplastic model by genetic algorithm, Materials \& Design, 31, pp. 1250-1255.

[18] Zhang, W., Cho, C., and Xiao, Y. (2014). An effective inverse procedure for identifying viscoplastic material properties of polymer Nafion, Computational Materials Science, 95, pp. 159-165. 
[19] Siviour, C. R., and Jordan, J. L. (2016). High Strain Rate Mechanics of Polymers: A Review, Journal of Dynamic Behavior of Materials, 2, pp. 15-32.

[20] Şerban, D. A., Weber, G., Marşavina, L., Silberschmidt, V. V., and Hufenbach, W. (2013). Tensile properties of semicrystalline thermoplastic polymers: Effects of temperature and strain rates, Polymer Testing, 32, pp. 413-425.

[21] Cao, K., Wang, Y., and Wang, Y. (2012). Effects of strain rate and temperature on the tension behavior of polycarbonate, Materials \& Design, 38, pp. 53-58.

[22] Nakai, K., and Yokoyama, T. (2008). Strain Rate Dependence of Compressive Stress-Strain Loops of Several Polymers, Journal of Solid Mechanics and Materials Engineering, 2, pp. 557-566.

[23] Viana, J. (2005). Structural interpretation of the strain-rate, temperature and morphology dependence of the yield stress of injection molded semicrystalline polymers, Polymer, 46, pp. 11773-11785.

[24] Lubarda, V. A., Benson, D. J., and Meyers, M. A. (2003). Strain-rate effects in rheological models of inelastic response, International Journal of Plasticity, 19, pp. 1097-1118.

[25] Manaia, J.P., Pires, F.A., de Jesus, A.M.P., Wu, S. (2019). Yield behaviour of high-density polyethylene: Experimental and numerical characterization, Engineering Failure Analysis, 97, pp. 331-353.

[26] Manaia, J.P., Pires, F.A., de Jesus, A.M.P. (2019). Elastoplastic and fracture behaviour of semi-crystalline polymers under multiaxial stress states, Frattura ed Integrita Strutturale, 13, pp. 82-103

[27] Riande, E. (2000). Polymer viscoelasticity: stress and strain in practice, 55, CRC Press.

[28] Ashrafi, H., and Farid, M. (2009). A mathematical boundary integral equation analysis of standard viscoelastic solid polymers, Computational Mathematics and Modeling, 20, pp. 397-415.

[29] Lemaitre, J., and Chaboche, J. L. (1994). Mechanics of Solid Materials, Cambridge University Press.

[30] Moutee, M., Fortin, Y., and Fafard, M. (2007). A global rheological model of wood cantilever as applied to wood drying, Wood Science and Technology, 41, pp. 209-234.

[31] Papanastasiou, T. C., and Boudouvis, A. G. (1997). Flows of viscoplastic materials: Models and computations, Computers \& Structures, 64, pp. 677-694.

[32] Otto, S., Denier, J.P. (2005). An introduction to programming and numerical methods in MATLAB. Springer Science \& Business Media,

[33] Schodek, D. L., Ferreira, P., and Ashby, M. F. (2009). Nanomaterials, nanotechnologies and design: an introduction for engineers and architects, Butterworth-Heinemann.

[34] Morin, D., Haugou, G., Lauro, F., Bennani, B., and Bourel, B. (2015). Elasto-viscoplasticity Behaviour of a Structural Adhesive Under Compression Loadings at Low, Moderate and High Strain Rates, Journal of Dynamic Behavior of Materials, 1, 124-135.

[35] Mulliken, A. D., and Boyce, M. C. (2006). Mechanics of the rate-dependent elastic-plastic deformation of glassy polymers from low to high strain rates, International Journal of Solids and Structures, 43, pp. 1331-1356.

[36] Srivastava, V., Chester, S. A., Ames, N. M., and Anand, L. (2010). A thermo-mechanically-coupled large-deformation theory for amorphous polymers in a temperature range which spans their glass transition, International Journal of Plasticity, 26, pp. 1138-1182.

[37] Bauwens-Crowet, C., Bauwens, J., and Homes, G. (1969). Tensile yield-stress behavior of glassy polymers, Journal of Polymer Science Part A-2: Polymer Physics, 7, pp. 735-742. 